\title{
A primary vertebral epithelioid osteosarcoma in middle age adult
}

\author{
Kyoungyul Lee ${ }^{1}$, Minsun Jung ${ }^{2}$, Young-Joon Ryu*1,3 \\ ${ }^{1}$ Department of Pathology, Kangwon National University Hospital, Chuncheon, Korea \\ ${ }^{2}$ Department of Pathology, Seoul National University Hospital, Seoul, Korea \\ ${ }^{3}$ Department of Pathology, College of Medicine, Kangwon National University, Chuncheon, Korea
}

Received: August 16, 2016

DOI: $10.5430 /$ crcp.v4n $1 \mathrm{p} 43$
Accepted: October 19, $2016 \quad$ Online Published: November 15, 2016

URL: http://dx.doi.org/10.5430/crcp.v4n1p43

\begin{abstract}
Primary vertebral epithelioid osteosarcoma is an extremely rare malignancy, characterized by predominant epithelioid cells and occurs mainly in adolescents and young adults. To our knowledge, only one previous report described a lumbar vertebral epithelioid osteosarcoma including the clinical information, pathologic features and immunohistochemical profile. This report is a first case of primary epithelioid osteosarcoma arising in the eighth thoracic vertebrae (T8) in middle aged man. Whole body scans as well as histological and immunohistochemical examinations were performed for excluding the possibility of metastatic malignancy or secondary osteosarcoma. Metastatic lesions showing the same morphological and immunohistochemical characteristics were demonstrated at the fifth lumbar vertebra (L5) and sternum were described 1 year after excision and high dose of Methotraxate (MTX) chemotherapy.
\end{abstract}

Key Words: Epithelioid osteosarcoma, Adult, Spine

\section{INTRODUCTION}

Osteosarcomas are the most common sarcomas, arising in the long bones metaphysis in adolescents and young adults. These lesions have been histologically classified into subtypes, including epithelioid, chondroblastic, fibroblastic, osteoblastic types etc. ${ }^{[1]}$ Because osteosarcoma is typically a metaphyseal lesion and occurring most commonly from ages at 10 to 25 years of ages, the vertebra is considered as an unusual site for osteosarcoma. Only one previous case of middle age man's epithelioid osteosarcoma was reported in second lumbar vertebra. ${ }^{[2]}$ In this report, we describe a first primary epithelioid osteosarcoma case arising in the thoracic vertebrae in middle aged man.

\section{CASE REPORT}

A 50-year-old man was admitted to Kangwon National University Hospital with sudden back pain. He had no past medical, family, or history of trauma. Radiologically, there was a $3.1 \mathrm{~cm}$ sized osteolytic lesion at the left posterior fifth thoracic vertebral body (T8) with focal cortical destruction (see Figure 1A). Whole body PET scanning was performed to exclude the possibility of metastatic condition. A posterior and anterior total enbloc spondylectomy and entire histologic examination were performed. The specimen consisted of multiple tan colored hemorrhagic bony and soft tissue fragments (see Figure 1B). On low power view, the tumor consisted of solid sheets of densely and uniformly

\footnotetext{
* Correspondence: Young-Joon Ryu, MD, PhD; Email: mindmader@ gmail.com; Address: Department of Pathology, College of Medicine, Kangwon National University, Chuncheon, Korea.
} 
proliferated cells with destroyed bone trabeculae (see Figure 1C). On high power view, most of the tumor cells showed similar sized epithelioid appearance with a vesicular nucleus and distinct nucleoli. The cytoplasm was fairly eosinophilic and its boundary was indistinct (see Figure 1D). The tumor cells also displayed a high mitotic rate with abnormal mitotic figures. On immunohistochemical (IHC) staining, all tumor cells showed strong immuno-positivity for vimentin, and some cells expressed high molecular weight cytokeratin
(HMW-CK), epithelial membrane antigen (EMA) and S100 protein (see Figure 2A-C), but negativity for Leukocyte common antigen (LCA), Human melanoma black (HMB45) and Murine double minute (MDM2) (see Figure 2D). After surgery, high dose Methotraxate (MTX) chemotherapy was given. However, metastatic lesion with the same microscopic and immunohistochemistry were described at the fifth lumbar vertebra (L5) and sternum after 1 year later.

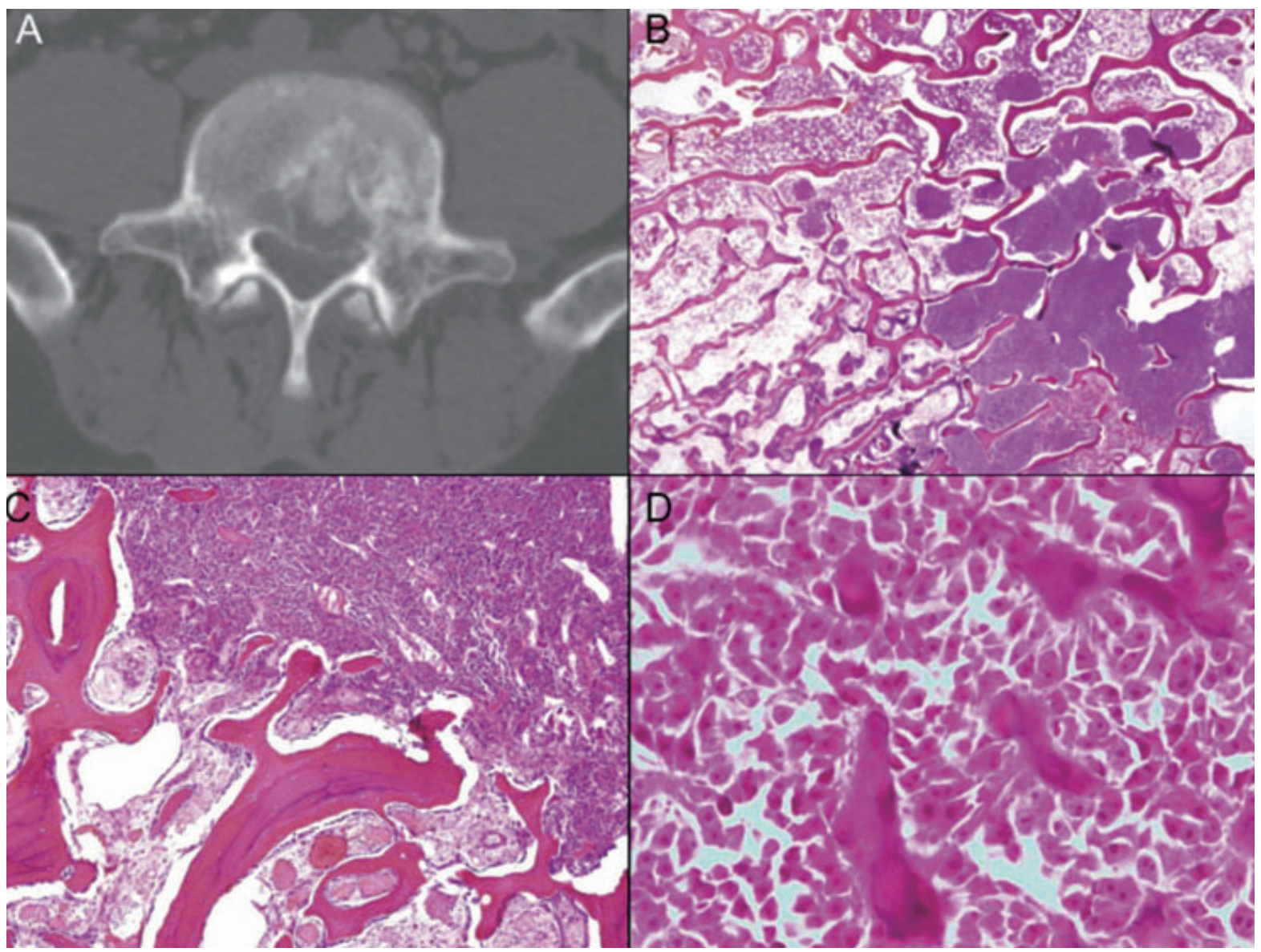

Figure 1. A: An osteolytic lesion in eighth vertebra (T8) is noted in computed tomogram; B: Solid sheets of tumor cells are present between bony trabeculae $(H \& E, \times 100)$; : Destructed bony structure by the tumor sheets $(H \& E, \times 200)$; D: Tumor cells showing vesicular nuclei and prominent nucleoli and forming osteoid $(\mathrm{H} \& \mathrm{E}, \times 600)$.

\section{Discussion}

A few number of maxillary or mandibular epithelioid osteosarcoma of middle-aged men were reported. ${ }^{[3-5]}$ However, only one previous primary epithelioid osteosarcoma in the spine was described, presented the clinic-pathological findings. The age and sex of this previously case (49-year-old man) was similar to this case. ${ }^{[2]}$

In the present case, the radiographic features of the affected spine showed an osteolytic lesion with cortical destruction, just similar to the conventional osteosarcoma. Cytologically, the cells were ovoid to polygonal cells with more or less a uniform size and shape with a conspicuous cytoplasm. Such cells morphologically mimic those of high grade malignancies, including carcinoma, melanoma, metastatic osteosarcoma, and large cell type lymphoma.

Although the immunophenotypic expression of epithelioid tumor cells is variable in previous literature review, ${ }^{[2-8]}$ the epithelioid tumor cells of the study case were strongly positive for vimentin, and focal positivity for HMW-CK, EMA and S-100 protein, but negative for LCA, HMB45 and MDM2. 


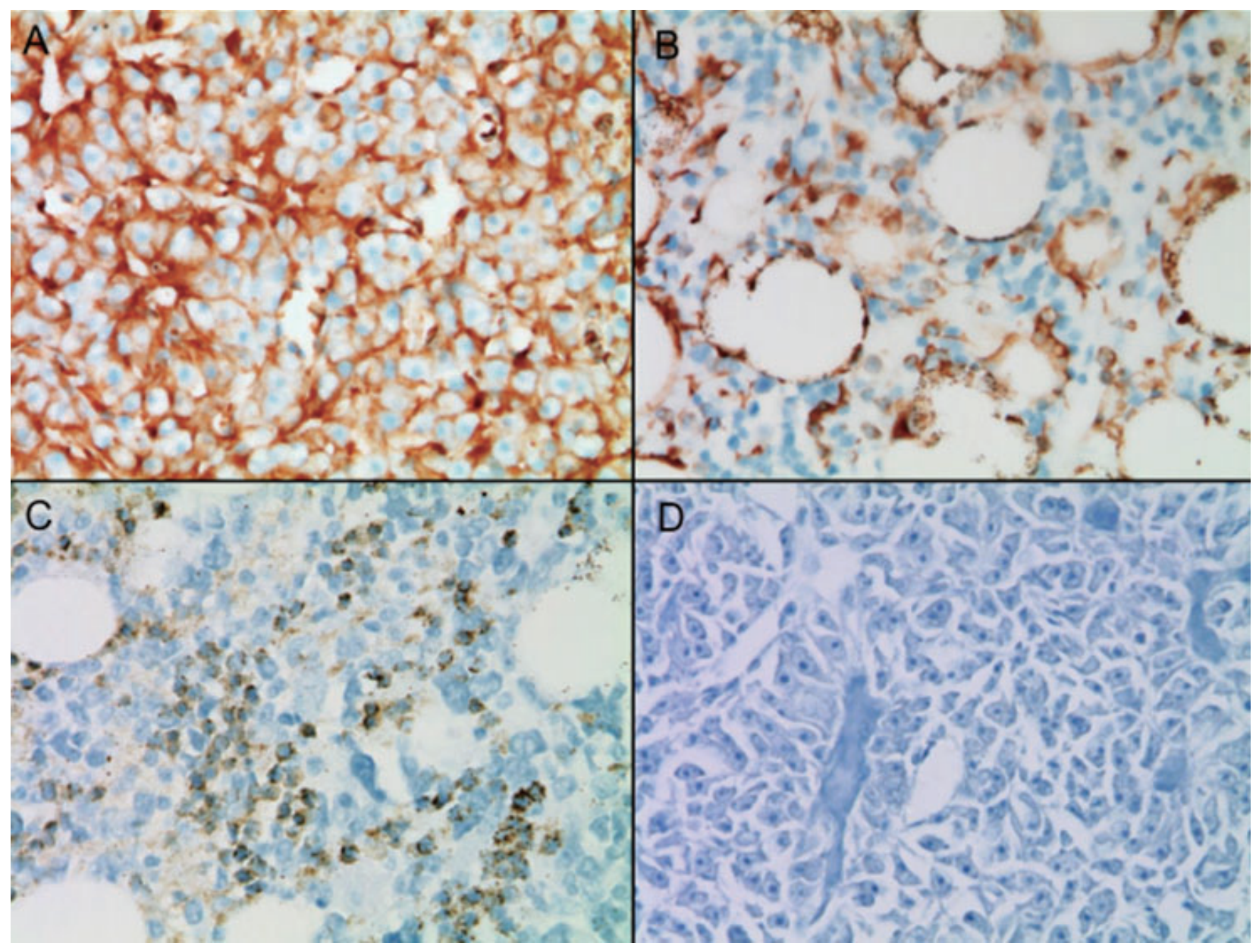

Figure 2. Tumor cells showing strong positivity for Vimentin (A), epithelial membrane antigen (EMA) (B) and focal positivity for S-100 protein (C), but negative HMB-45 (D). (Immunohistochemistry, $\times 600$ )

The treatment of osteosarcoma is a combination of surgery, chemotherapy, and radiation therapy, but surgical excision was a mainstay of our treatment. Clear resection margins are associated with a considerably higher 5 -year survival rate. ${ }^{[9]}$ Chemotherapy is usually tried after surgery, its effects have yet to be unequivocally demonstrated. Due to a limited number of reports, however, exact prognosis for epithelioid osteosarcoma remains unclear. Nonetheless, some previous studies have reported that osteosarcoma with epithelioid features is associated with an aggressive clinical behavior. ${ }^{[10,11]}$ In this case, tumor cells also showed aggressive behavior with multiple bony metastases.

\section{FUNDING}

This report was supported by 2013 Research Grant of Kangwon National University. The control tissue for this study was provided by the Kangwon National University Hospital Biobank, a member of the National Biobank of Korea, which is supported by the Ministry of Health, Welfare and Family Affairs.

\section{CONFlicts of Interest Disclosure}

The authors declared no potential conflicts of interest with respect to the research, authorship, and/or publication of this article.

\section{REFERENCES}

[1] Fletcher C, Unni KK, Mertens F. World Health Organization Classification of Tumors. Pathology and Genetics. Tumours of Soft tissue and Bone. IARC press. 2013. 281-96p.

[2] Hasegawa T, Shibata T, Hirose T, et al. Osteosarcoma with epithe- lioid features. An immunohistochemical study. Arch Pathol Lab Med. 1993; 117: 295-8. PMid: 7680195. http://www.ncbi.nlm.nih .gov/pubmed/7680195

[3] Okada K, Hasegawa T, Yokoyama R. Rosette-forming epithelioid osteosarcoma: a histologic subtype with highly aggressive clini- 
cal behavior. Hum Pathol. 2001; 32: 726-33. PMid: 11486171. http://dx.doi.org/10.1053/hupa.2001.25585

[4] Rinaggio J, Kewitt GF, McGuff HS. Epithelioid osteosarcoma presenting as a rapidly expanding maxillary mass. Head Neck. 2007; 29: 705-9. PMid: 17230564. http://dx.doi.org/10.1002/hed .20575

[5] Carlos-Bregni R, Contreras E, Hiraki KR, et al. Epithelioid osteosarcoma of the mandible: a rare case with unusual immunoprofile. Oral Surg Oral Med Oral Pathol Oral Radiol Endod. 2008; 105: e47-52. PMid: 18230378. http://dx.doi.org/10.1016/j.tripleo.2 007.09 .003

[6] Cozza R, Devito R, De Ioris MA, et al. Epithelioid osteosarcoma of the jaw. Pediatr Blood Cancer. 2009; 52: 877-9. PMid: 19202567. http://dx.doi.org/10.1002/pbc. 21894

[7] Ladanyi M, Cha C, Lewis R, et al. MDM2 gene amplification in metastatic osteosarcoma. Cancer Res. 1993; 53: 16-8. PMid:
8416741.

[8] Kaveri H, Rekha K, Punnya VA. Epithelioid osteosarcoma of the maxilla: report of an unusual case. Br J Oral Maxillofac Surg. 2009; 47: 143-5. PMid: 18762359. http://dx.doi.org/10.1016/j.b joms. 2008.07.188

[9] Sturgis EM, Potter BO. Sarcomas of the head and neck region. Curr Opin Oncol. 2003; 15: 239-52. PMid: 12778019. http: //dx.doi.org/10.1097/00001622-200305000-00011

[10] Okada K, Hasegawa T, Yokoyama R, et al. Prognostic relevance of rosette-like features in osteosarcoma. J Clin Pathol. 2003; 56: 831-4. PMid: 14600127. http://dx.doi.org/10.1136/jcp.56.11.8 31

[11] Rinaggio J, Kewitt GF, McGuff HS. Epithelioid osteosarcoma presenting as a rapidly expanding maxillary mass. Head Neck. 2007; 29: 705-9. PMid: 17230564. http://dx.doi.org/10.1002/hed .20575 